\title{
Team-based Learning in Pharmacy: The Faculty Experience
}

\author{
Authors: Simon Tweddell ${ }^{1}$, David Clark $^{2}$, Michael Nelson $^{3}$ \\ 1.Bradford School of Pharmacy, University of Bradford, Bradford. West Yorkshire, United Kingdom \\ 2.Department of Pharmacy Practice, Regis University Rueckert-Hartman College for Health \\ Professions School of Pharmacy, Denver, CO. \\ 3.Department of Pharmaceutical Sciences, Regis University Rueckert-Hartman College for Health \\ Professions School of Pharmacy, Denver, CO.
}

Background: One U.S. School of Pharmacy introduced a new highly-integrated PharmD programme in 2009 , delivered predominately by team-based learning (TBL). Given the increased pedagogical complexity of TBL relative to lecture-based learning, it is likely that the experiences of TBL implementation on pharmacy faculty differs from the experiences associated with more traditional learning models. This study uses qualitative research methodology to explore the faculty experience and lessons learned from a large-scale implementation of TBL in an integrated pharmacy curriculum.

Description: Following IRB approval, 19 faculty at one U.S. School of Pharmacy participated in a 30-minute one-to-one semi-structured interview. The interviewer explored faculty perceptions, experiences and lessons learned from introducing TBL as the main instructional method in the PharmD program. Interviews were transcribed and the data analysed with qualitative methodology (thematic analysis) using qualitative and mixed-method research software (NVivo).

Results: Faculty perceived TBL to be beneficial to student learning. Students came to class prepared and ready to and participate in and actively engage in problem solving through application exercises. TBL is helping students develop the softer skills needed in the workplace. There was some concern that students might rely too much on team-work and not be able to work as well independently.

Faculty perceptions were that TBL is more work for them than traditional methods, especially the first iteration. Areas faculty found most challenging were writing effective application exercises and the development of TBL facilitation skills. Faculty's understanding of pedagogical approaches and educational theory improved as a result of using TBL.

Conclusion: Despite the challenges there was resounding support for TBL among faculty, leading to the conclusion that the benefits of TBL far outweighing the challenges. The study identified a number of lessons learned that may be of benefit to other educators considering introducing TBL in pharmacy curricula. 